\title{
The Past and Current Status of Dentists in Japan
}

\author{
Masaru Sugiyama', Rumi Nishimura², Myung-Jin Lee ${ }^{3}$, and Sang-Hwan $\mathrm{Oh}^{4, \dagger}$ \\ ${ }^{1}$ Graduate School of Biomedical and Health Sciences, Hiroshima University, Hiroshima 734-8553, ${ }^{2}$ Department \\ of Oral Epidemiology, Graduate School of Biomedical and Health Sciences, Hiroshima University, Hiroshima \\ 734-8553, Japan, ${ }^{3}$ Department of Dental Hygiene, Division of Health Science, Baekseok University, Cheonan \\ 31065, ${ }^{4}$ Department of Dental Hygiene, College of Medical Science, Konyang University, Daejeon 35365, Korea
}

\begin{abstract}
The purpose of this study is to provide the general history of fostering dentists in Japan and introducing their new roles. This research was conducted based on the government policy report on dentists and the information published by each educational institution. Based on the collected data, the official websites were used to represent the latest statistics of the institutions. The number of dentists in Japan has increased. The government established the National Examination for Dentists to guarantee the quality of dentists. After the standards for developing questions for the national examination were established in 1985, the contents of the examination have been appropriately improved by revising the standards every four years. This improvement has required dental students to study a variety of subjects for six years at dental school. Since dentists in Japan are required to respond to various demands from the nation; the Model Core Curriculum for Dental Education was developed to teach medical ethics and abilities to ensure that dentists conduct themselves professionally. Recently, the roles of dentists have been changing in Japan. When providing dental services to older patients over the age of 65 , dentists and other dental professions focus on maintaining oral functions, such as saliva secretion, bite force, tongue movement, and masticatory/swallowing functions. However, oral function-related services for children are different. In addition to providing essential dental services, dental practitioners also provide special treatment, such as oral muscle training, myofunctional therapy, health guidance, and space retainers to the child patients with developmental insufficiency in oral functions. Dentistry in Japan has undergone numerous changes over the years and has continued to offer high-quality dental health services. Thus, information gained from the Japanese experience may be helpful to dental professions in other developed countries for planning oral health measures.
\end{abstract}

Key Words: Curriculum, Dentist, Japan, National examination, Work place, Work role

\section{Introduction}

After the Meiji Restoration in 1986, Japanese pioneers studied dentistry from American dentists and introduced modern dentistry into Japan ${ }^{1)}$. Soon after World War II, a variety of reforms led to the establishment of the new Dentist Act and the Dental Hygienist Act under the direction of the General Head Quarters of the Allied Forces $^{2)}$. The Ministries of Education and Health subsequently strived to improve the nation's oral health by fostering well-trained dental professions, establishing good medical care systems, and so on. As a result, the percentage of children with decayed teeth has significantly decreased and the elderly $\geq 80$ years with $\geq 20$ teeth have also increased remarkably ${ }^{3)}$. Recently, in Japan, maintaining and improving a variety of oral functions throughout the patient's lifespan has been recognized as an important consideration for lifelong health ${ }^{4,5)}$.

This study aimed to provide some useful information for dental professions seeking better dental education and dental care systems by discussing the status of dentists in Japan and in particular, focusing on the dental education system and the roles of dentists. 


\section{History of Fostering Dentists in Japan}

The Japanese history of dentists is summarized in Table 1. The first Japanese dentist was Mr. Einosuke Obata. He studied dentistry under an American dentist who came to Japan ${ }^{1)}$. Subsequently, Mr. Obata passed the examination for medical practitioners which was first conducted in 1875, and he registered as a medical doctor who specialized in dentistry. He devotedly taught dentistry to the younger generations but he did not establish an educational institution for dentistry. In 1883, the examination rules for medical practitioners were established and dentistry was added). Since then, passing this examination has been mandatory to become a dentist. The registration system of authorized dentists began at the same time.

The first Japanese dental school, Takayama Dental School, was established in 1889 by Mr. Kisai Takayama who studied dentistry in the US ${ }^{1)}$. That school is presently named Tokyo Dental College. Mr. Takayama also wrote a Japanese study guide for dentistry.

In 1903, the former Japan Dental Association was established and in 1096, the former Dentist Act was established $^{1)}$. Since then, eight dental schools were established until the end of World War II ${ }^{1)}$. In 1913, examination rules specifically for dentists were established. These rules prescribed that examinees must have studied for more than three years at a dental school ${ }^{1)}$.

In 1946, one year after the war ended, the new national examination systems for medical doctors, dentists, and pharmacists commenced, while the new Dentist Act was

Table 1. History of Fostering Dentist in Japan ${ }^{1)}$

\begin{tabular}{cl}
1875 & $\begin{array}{c}\text { A dentist was registered after passing the 1st } \\
\text { examination for medical practitioners. } \\
\text { Dentistry was added to the examination for medical } \\
\text { practitioners. }\end{array}$ \\
1883 & $\begin{array}{c}\text { Dental school was first established. } \\
1906\end{array}$ Establishment of the former Dentist Act \\
1913 & The examination rules for dentists were established. \\
1946 & $\begin{array}{c}\text { The new national examination systems for dentists } \\
\text { started. }\end{array}$ \\
1948 & $\begin{array}{c}\text { Establishment of the present Dentist Act } \\
\text { 1-year clinical training became mandatory for all the } \\
\text { dentists newly registered. }\end{array}$ \\
\hline
\end{tabular}

established in $1948^{1)}$. The new examination system required the examinees to have studied for more than six years at a dental school. To address the shortage of dentists at the time, dental schools were established one after another. By 1979, there were 29 dental schools comprising 17 private universities, 11 national universities, and one prefectural university ${ }^{6}$. The admission capacity also increased in many of the schools until the total admission capacity in 1980 reached five times that of $1960^{3)}$. In 1984, the government's goal for the number of dentists to reach 50 per 100,000 population was achieved ${ }^{7)}$. In 1986, the committee in the Ministry of Health discussed the supply and demand of dentists and in 1987, the Ministry of Education proposed a $20 \%$ reduction in the total admission capacity ${ }^{7)}$. In 1998, an additional a $10 \%$ reduction was proposed ${ }^{7)}$. Subsequently, the $20 \%$ reduction was accomplished but the additional $10 \%$ reduction has not been accomplished yet ${ }^{7)}$.

In 1985, the standards for developing and selecting questions for the National Examination for Dentists were established and they have been revised every four years ${ }^{8)}$. Recently, the contents of the standards have been improved vigorously, because dentists are required to respond to the various needs of the nation. In 2001, the Meeting of the Researchers who Participated in the Study on Medical and Dental Education reported on the measures for improving medical and dental education in the 21st century ${ }^{9)}$. Based on the report, the Model Core Curriculum for Dental Education was established and it has been revised three times so far ${ }^{9)}$. In 2005, computerbased testing (CBT) and objective structured clinical examination (OSCE) were officially introduced to examine the knowledge and skills of dental students before they began clinical practice ${ }^{10}$. The students who passed both the CBT and OSCE are qualified as a student dentist and are allowed to participate in clinical practice ${ }^{10)}$.

In 1987, optional clinical training of newly registered dentists started in dental school hospitals to improve the ability for primary care. In 2006, this training became mandatory for all newly registered dentists ${ }^{1)}$. Currently, dentists can receive their training at private clinics as well as hospitals (Fig. 1) ${ }^{3)}$. 


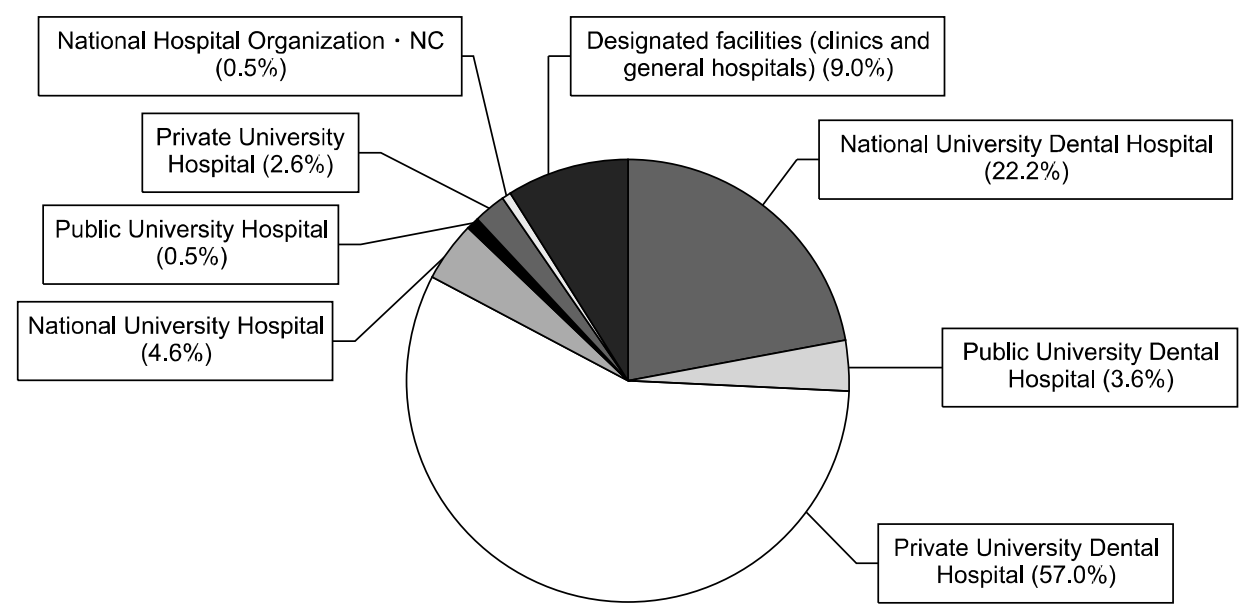

Fig. 1. Facilities where resident dentists have clinical training ${ }^{3)}$. NC: National Research Center for Advanced and Specialized Medical Care Systems.

\begin{tabular}{|c|c|c|c|}
\hline \multicolumn{4}{|c|}{ Basic qualities and abilities required for dentists (medical knowledge, clinical skills etc.) } \\
\hline \multicolumn{4}{|c|}{ Society and dentistry (prophylaxis and health management, epidemiology etc.) } \\
\hline $\begin{array}{l}\text { Life science } \\
\text { (anatomy, physiology, pathology, } \\
\text { molecular biology, microbiology, } \\
\text { immunology, pharmacology etc.) }\end{array}$ & \multirow{2}{*}{$\begin{array}{l}\qquad \text { Clinical dentistry } \\
\text { 1. Basic clinical skills } \\
\text { 2. Normal conditions and diseases of } \\
\text { the teeth, periodontal tissues and } \\
\text { oro-maxillofacial regions } \\
\text { 3. Special needs dentistry } \\
\text { 4. Medical knowledge }\end{array}$} & \multirow{2}{*}{$\begin{array}{l}\mathrm{C} \\
\mathrm{B} \\
\mathrm{T} \\
\dot{\mathrm{O}} \\
\mathrm{S} \\
\mathrm{C} \\
\mathrm{E}\end{array}$} & \multirow{2}{*}{$\begin{array}{l}\text { Clinical } \\
\text { practice }\end{array}$} \\
\hline $\begin{array}{c}\text { Dental material science } \\
\text { (dental materials and devices) }\end{array}$ & & & \\
\hline
\end{tabular}

Fig. 2. The outline of the Model Core Curriculum for Dental Education ${ }^{11)}$. CBT: computer-based testing, OSCE: objective structured clinical examination.

\section{Model Core Curriculum}

As described above, the Model Core Curriculum for Dental Education was established in 2001 at the Meeting of the Researchers who Participated in the Study on Medical and Dental Education and the curriculum was revised in 2007, 2011, and 2016 ${ }^{9}$. The latest version of the Model Core Curriculum for Dental Education concept is described below and the outline of the curriculum is shown in Fig. $2^{11)}$.

\section{Background and basic concept}

The latest version is themed, "Cultivation of dentists who can respond to various needs of the nation" "9). The "various needs" in this theme refers to the need for dentists to have the medical ethics and abilities for their roles in the medical safety system, team care, integrated community care, and healthy aging society. To achieve these goals, improvement in the following items are required:

- Evaluation of attitudes and clinical skills at various clinical settings at the end of clinical practice

- Internationalization in the dental field

- Contribution of dentists to home care, professional care, and aid in natural disasters

- The ability of understanding the patient's general condition and promoting team care

- Consistent education before and after graduation from the dental school

- Quality assurance in higher dental education

In 2004, an accreditation system was first introduced in Japan, after the School Education Act was revised ${ }^{9)}$. The system was introduced into pharmaceutical education in 2013 and medical education in 2015. Since 2012, trial evaluations have been ongoing in dental education as well ${ }^{9)}$. 
2. The opinions from the Meeting of the Researchers who Participated in the Study on Medical and Dental Education

The meeting considered that the dental education program of each school should consist of $60 \%$ of its own curriculum based on the Model Core Curriculum and $40 \%$ based on its characteristic plan ${ }^{9)}$. The Meeting proposed that all dental schools should share educational materials, methods, and guidelines, especially the guidelines for clinical practice.

\section{National Examination for Dentists}

In order to become a dentist in Japan, examinees are required to pass the National Examination for Dentists after studying for six years in a dental school ${ }^{1)}$. After passing the examination, newly registered dentists must also receive at least one year of clinical training ${ }^{1)}$. The details of the Japanese National Examination for Dentists are shown in Table $2^{12)}$.

The National Examination for Dentists covers the essential knowledge and skills regarding dentistry required in clinical settings and oral health. However, the contents of the examination have recently changed to include the theme, "Cultivation of dentists to respond to the various needs of the nation" " Characteristic changes in the standards for developing and selecting questions for the National Examination are as follows:

- In 2010: improvement of questions relating to i) the relationship between the oral cavity and the whole body; ii) the management of the elderly and patients with general/ systemic diseases; and iii) the preventive management of dental diseases ${ }^{13)}$.

- In 2014: improvement of questions relating to i) the management of the elderly and patients with general/ systemic diseases; ii) the preventive management of dental diseases; iii) social security system; iv) the relationship between the oral cavity and the whole body; and v) dental care and forensic dentistry during natural disasters ${ }^{14)}$.

There were also additional questions on i) child abuse; ii) medical safety system including infection control; iii) influence of radiation on the human body; and iv) English required for dental treatment ${ }^{14)}$.

- In 2018: improvement of questions relating to i) integrated community care and cooperation with other professionals; ii) improvement of oral functions and treatment of eating disorders; iii) medical safety system and emergency response; and iv) professional ethics ${ }^{15}$.

Since 2004, the percentage of successful examinees has decreased significantly. Since 2013, the passing rate has been approximately $65 \%{ }^{16}$. This is partially because the recent National Examination has become more difficult after including questions that require knowledge of various settings and in part due to the multiple-choice questions that have multiple correct answers. There is also another view suggesting that the percentage of successful examinees is kept low to decrease the total number of dentists $^{7}$.

Table 2. Details of Japanese National Examination for Dentists ${ }^{12)}$

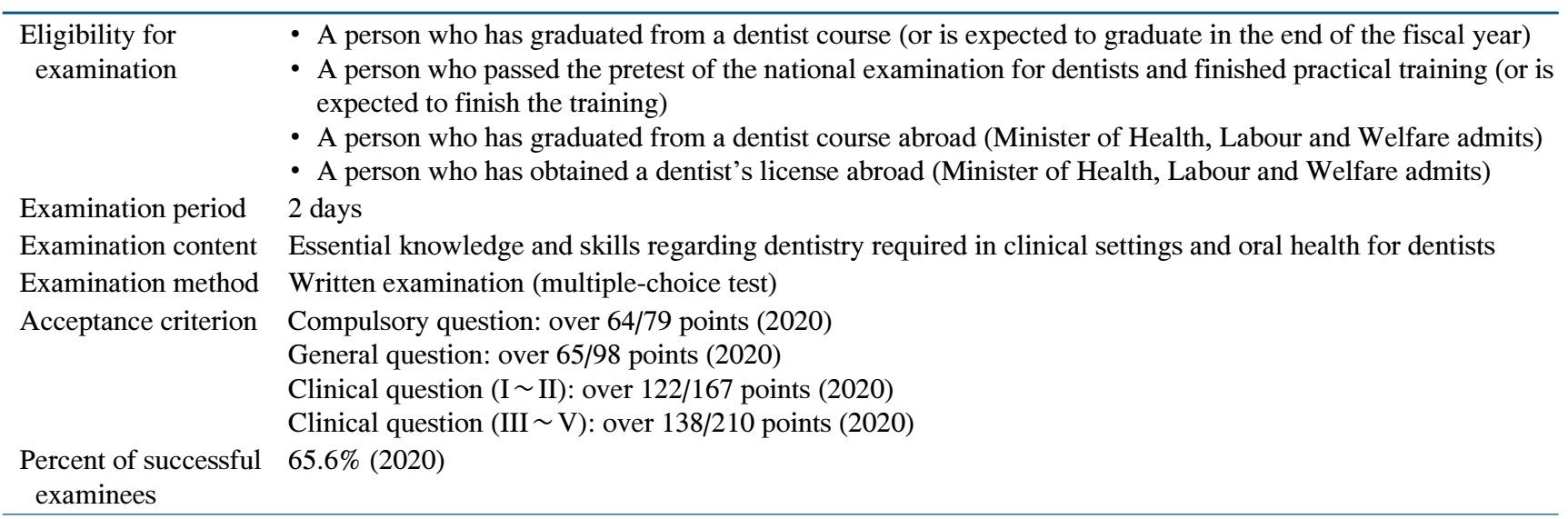




\section{The Roles of Dentists}

\section{Background}

In Japan, both the number of elderly and the number of elderly $\geq 80$ years with $\geq 20$ teeth have increased. In 2011 , the percentage of elderly over 80 years of age with $\geq 20$ teeth reached about $40 \%{ }^{3)}$. The percentage of children with decayed teeth has also decreased significantly (Fig. 3) ${ }^{3)}$. Fig. 4 shows the percentages of the annual numbers of crowns, bridges, partial, and complete dentures compared to the numbers of each prosthetic appliance in 1998. Since 2005, the percentages of crowns, partial dentures, and complete dentures have clearly decreased, whereas the percentage of bridges have gradually decreased $^{3)}$. The above mentioned changes have been significantly influenced by the demands from patients and society. The 2005 survey (the Predictive Study on Demands for Dental Treatment in the New Era) conducted by the Ministry of Health reported that demands for preventive, implant, and geriatric dentistry would increase in the future and that the demands for pediatric, conservative, and prosthetic dentistry would decrease (Fig. 5, 6) ${ }^{3)}$. To deal with these demands from patients, society, and dentists properly, Japanese medical insurance has been revised every two years ${ }^{17}$. Among all the revisions, the most characteristic ones are oral functionrelated services and medical cooperation system leading to comprehensive community care. We will explain these

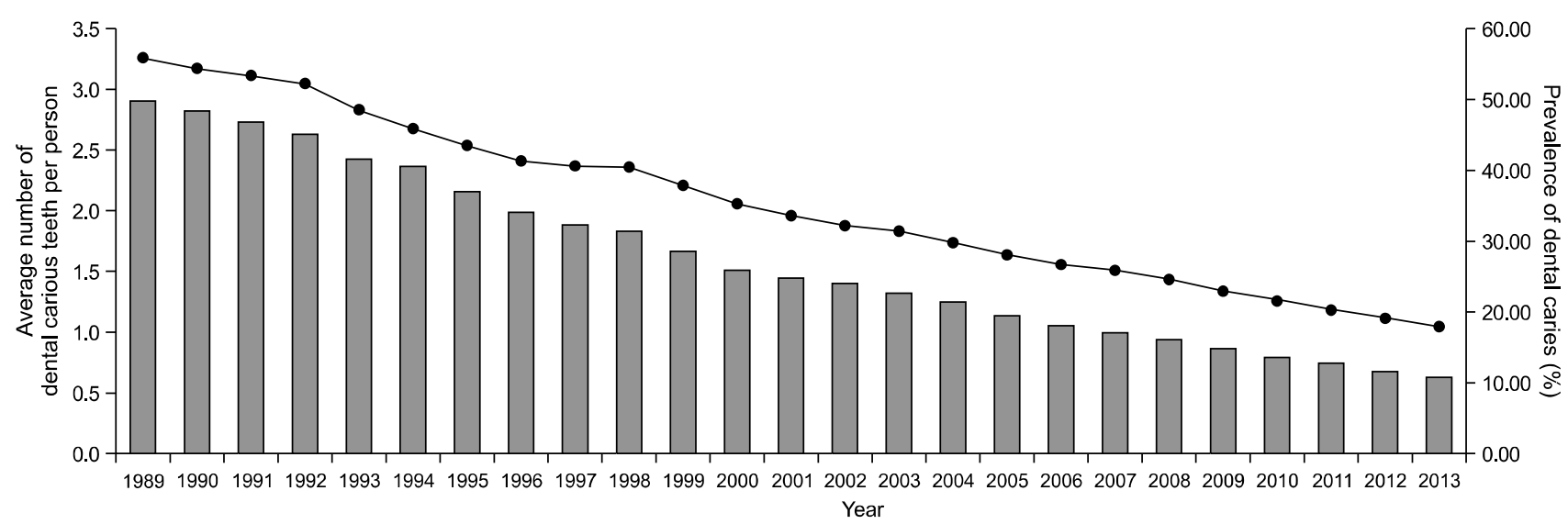

\begin{tabular}{|c|c|c|c|c|c|c|c|c|c|c|c|c|c|c|c|c|c|c|c|c|c|c|c|c|c|}
\hline$\square$ & 2.9 & 2.8 & 2.7 & 2.6 & 2.4 & 2.4 & 2.2 & 2.0 & 1.9 & 1.8 & 1.7 & 1.5 & 1.5 & 1.4 & 1.3 & 1.2 & 1.1 & 1.1 & 1.0 & 0.9. & 0.9 & 0.8 & 0.7 & 0.7 & 0.6 \\
\hline- & 55.76 & 54.32 & 53.32 & 52.21 & 48.35 & 45.78 & 43.40 & 41.23 & 40.49 & 40.41 & 37.85 & 35.23 & 33.60 & 32.25 & 31.35 & 29.81 & 28.01 & 26.64 & 25.86 & 24.56 & 22.95 & 21.54 & 20.31 & 19.08 & 17.92 \\
\hline
\end{tabular}

Fig. 3. Percentages of children with decayed tooth and mean values of decayed tooth in children $^{3)}$.

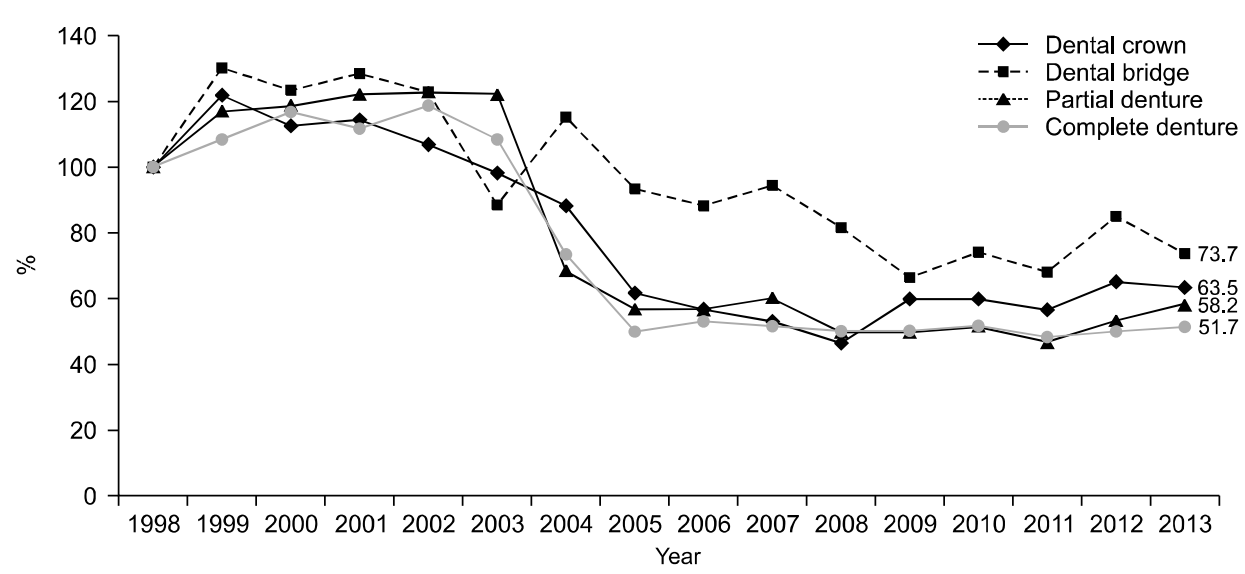

Fig. 4. Percentages of annual case numbers of crown, bridge, and partial and complete denture compared to those in $1998^{3)}$. 


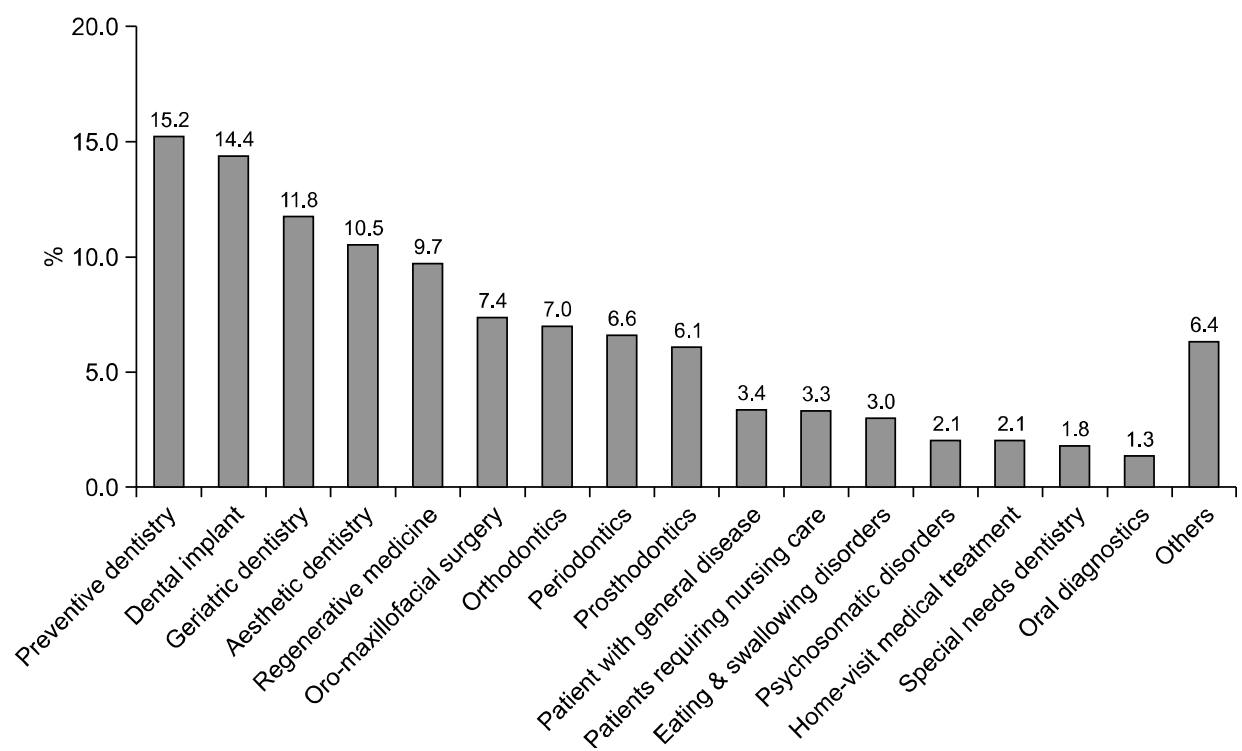

Fig. 5. Fields where demands are expected to increase in future ${ }^{3)}$.

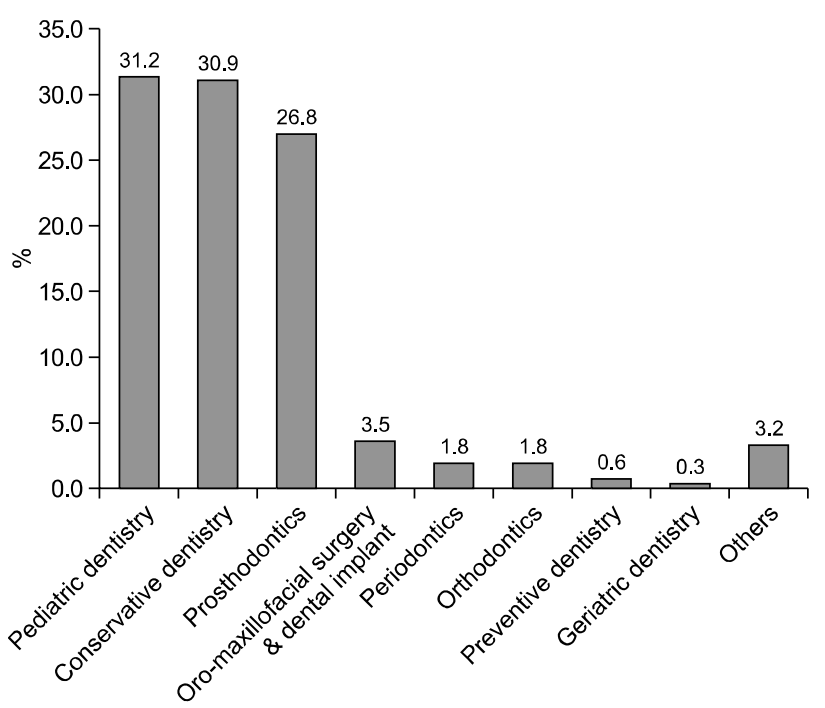

Fig. 6. Fields where demands are expected to decrease in future ${ }^{3)}$.

revisions in the following sections.

\section{Oral function-related services that are newly added to medical insurance}

\section{1) Management of oral functions in the elderly}

In order to recover, maintain, or improve oral functions such as saliva secretion, bite force, tongue movement, and masticatory/swallowing functions, this service is provided to patients over 65 years of age who show deterioration of oral functions due to tooth loss, aging, or general diseases $^{4)}$. To be eligible for this service, patients must be diagnosed as having oral hypofunction, with reduced abilities in mastication, bite-force, or tongue pressure, based on the diagnostic criteria defined by the relevant associations $^{4)}$. For patients with poor oral hygiene, dental professionals must not only provide instructions for oral hygiene but also explain that good oral hygiene leads to a healthy long life ${ }^{4)}$. For the patients with low bite force, dental professionals train masticatory muscles to maintain and/or improve the bite force in addition to providing prosthetic treatment ${ }^{4}$. For the patients showing hypofunction of the lip and tongue, dental professionals provide instructions for strengthening the muscles with specific apparatus to improve lip closure and tongue pressure, and assist with expanding the range of lip/tongue movements and the ability to pronounce monosyllables such as /pa/, $/ \mathrm{ta} /$, and $/ \mathrm{ka} /{ }^{4}$. Additionally, the dental professionals explain the importance of social activities and motivate the patients to maintain or improve their activities, because it has been shown that a reduction in social activities may lead to social frailty ${ }^{4)}$. For the patients with poor masticatory function, dental professionals train mastication with training food ${ }^{4)}$. 


\section{2) Management of oral functions in children}

In order to make children acquire normal oral functions such as eating, speaking, and breathing, this service is provided to the child patients under 15 years of age who show developmental insufficiency of oral functions ${ }^{5)}$. To be eligible for this service, patients must be diagnosed as having developmental insufficiency of their oral functions based on the diagnostic criteria defined by the relevant associations ${ }^{5)}$. This service varies diversely depending on each child's developmental stage and which function shows developmental insufficiency.

- In patients with insufficiency of their masticatory function, the following measures are implemented after developmental stage 4 (at around $3 \sim 6$ years of age). However, in the early stages of insufficiency, follow-up and guidance on health and food selections are the main measures ${ }^{5)}$ :

i) Training of the orofacial muscles in patients with insufficient lip closure during mastication.

ii) Myofunctional therapy for patients with insufficient tongue movement.

iii) Health guidance on oral hygiene and meals/snacks, and treatment of decayed teeth in patients with dental caries.

- In patients with insufficiency of their swallowing function, when dental professionals deal with patients who have insufficient swallowing function, cooperation with other professionals is extremely important, especially in severe cases. The dental professionals can contribute to the care of these patients by providing the following services $^{5)}$ :

i) Instruction on baby feeding at developmental stage 1 (before weaning).

ii) Swallowing training after developmental stage 2 .

- In patients with speaking insufficiency, follow-up is the first-line care until approximately 3 years of age ${ }^{5)}$ :

i) Articulation training in long-suffering or remarkable cases.

ii) Introducing the patients to specialists in the case of speaking insufficiency caused by otolaryngologic disorders or anomalies of the central nervous system.

iii) Dental treatment or training in the cases of articulation disorders. iv) Myofunctional training in the cases of thumb or finger sucking, or tongue thrusting.

v) Dental treatment or training in the case of anomalies of the tongue frenulum affecting articulation.

- In patients with insufficiency in their physical development:

i) In the case of extremely poor physical development, health guidance on food contents or diet should be provided in cooperation with pediatricians and registered dieticians ${ }^{5}$.

- In patients with breathing issues:

i) Guidance and management for acquiring appropriate oral functions and normal maxillofacial development ${ }^{5}$.

ii) Training for improving functions of predation, mastication, and speaking during moderate oral breathing. The patient should be referred to a pediatrician or otolaryngologist if the issues are severe ${ }^{5)}$.

\section{Therapy for eating disorders}

This therapy is given to patients with eating disorders. The dental hygienist, nurse, or physical, occupational, and speech therapist provide training to the patient for more than 30 minutes under the supervision of a dentist or medical doctor ${ }^{18)}$. Patients with eating disorders are defined as follows: i) those with the disorder due to developmental retardation or sequelae of surgery with maxillectomy/mandibulectomy and tongue excision or cerebral stroke; ii) those with the disorder that has been objectively confirmed by video endoscopic or videofluorographic examination and those who are expected to improve after the therapy. The measures and therapy for eating disorders are the same as for the management of oral functions ${ }^{19}$.

\section{Medical cooperation system and comprehensive community care}

Historically, the first cooperative medicine covered by medical insurance is the "service of providing medical information" which was introduced in $1996^{17)}$. Since then, other cooperative medical services such as "medical management service during dental treatment"20) and "cooperative guidance to in-home patients" $" 21)$ have been covered by medical insurance. In the beginning, medical 
cooperation mainly involved the medical doctors and dentists. More recently, professional cooperation has extended to include a variety of health professionals including nurses and dental hygienists ${ }^{21,22)}$. This type of professional cooperation is essential for establishing a community-based comprehensive medical care system (Fig. 7).

\section{Work Locations of Dentists}

The total number of dentists has increased annually even after the admission capacity of dental students was reduced because of a surplus number of dentists in Japan ${ }^{7)}$. Currently, the number of dentists per 100,000 population is at $80.5^{23)}$. Fig. 8 shows that the number of dentists working at private dental office has increased significantly, but those at other facilities has not ${ }^{23)}$. Interestingly, the number of dentists working at elderly facilities is $0.0 \%$. This means that dental treatment for patients at elderly facilities is provided by visiting dentists from private offices or hospitals (Table 3$)^{23)}$.

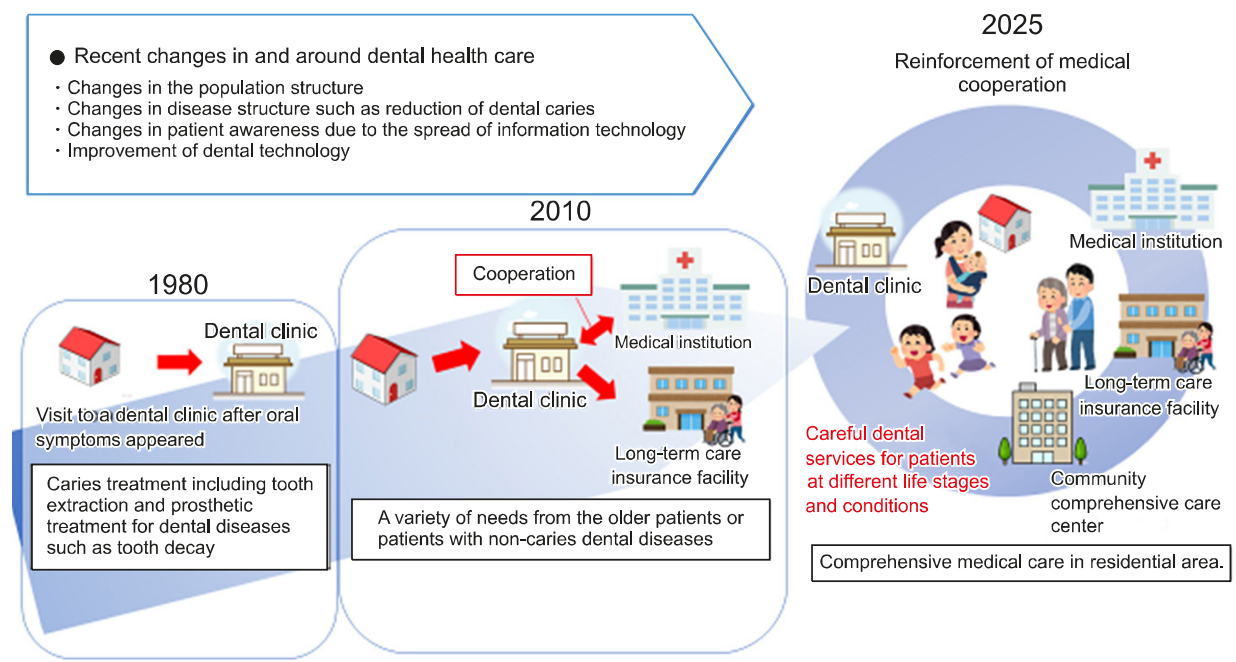

Fig. 7. Changes of Dental Care Service ${ }^{3)}$. In around 1980, dental professions mainly needed to treat caries-related dental diseases. In around 2010 , dentists turned to treat elderly patients or patients with other dental diseases in cooperation with medical institution and nursing homes. In around 2025, dentists are expected to play an important role in community comprehensive care.

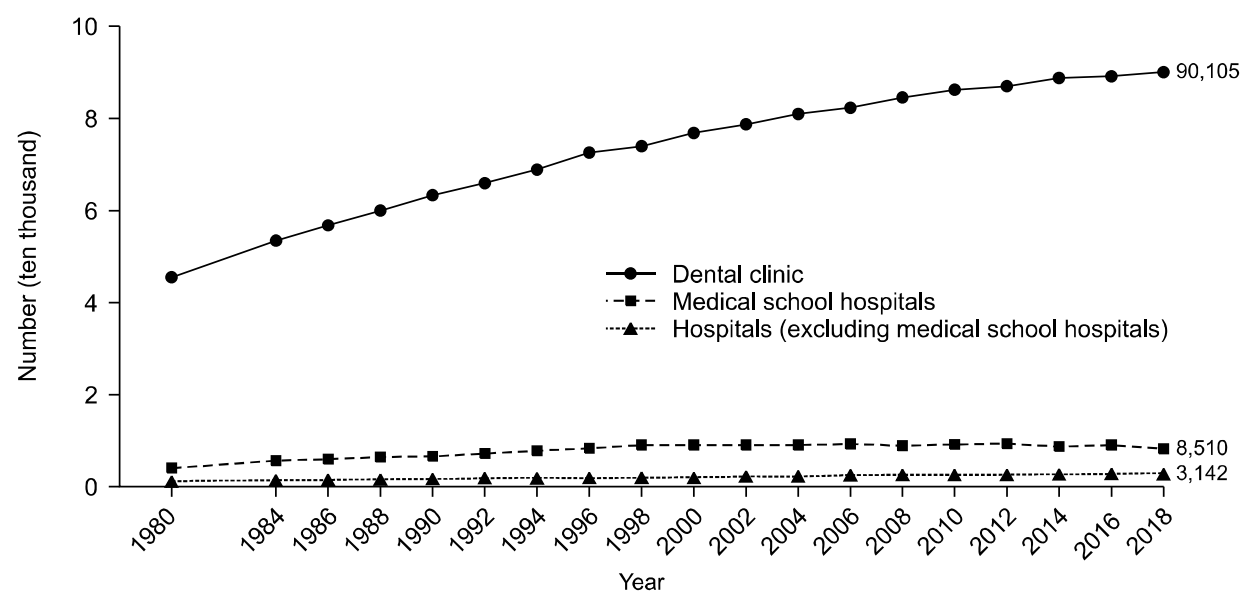

Fig. 8. Seasonal changes in the number of dentists working at each occupation ${ }^{23)}$. 
Table 3. Percentage of Dentists at Each Occupation in the National Survey ${ }^{23)}$

\begin{tabular}{|c|c|c|c|}
\hline \multicolumn{3}{|c|}{ Private dental office } & $85.9 \%$ \\
\hline \multirow[t]{7}{*}{ Others } & Hospital & $11.1 \%$ & $14.1 \%$ \\
\hline & $\begin{array}{l}\text { Teachers in basic sciences at } \\
\text { medical educational institute }\end{array}$ & $0.9 \%$ & \\
\hline & $\begin{array}{l}\text { Teachers in basic sciences at } \\
\text { non-medical educational institute } \\
\text { or research institute }\end{array}$ & $0.2 \%$ & \\
\hline & Health office & $0.4 \%$ & \\
\hline & Healthcare facility for the elderly & $0.0 \%$ & \\
\hline & $\begin{array}{l}\text { Postgraduate students in basic } \\
\text { sciences at medical educational } \\
\text { institute }\end{array}$ & $0.1 \%$ & \\
\hline & Others & $1.4 \%$ & \\
\hline
\end{tabular}

\section{Conclusion}

Dentistry in Japan has undergone characteristic changes over the years, partly due to a surplus number of dentists since around $1985^{7)}$ and partly due to Japan being a super-aged society since $2007^{24)}$. As a result, the national examination has become more difficult because the national government required dentists to have more knowledge to respond to a variety of needs of the nation ${ }^{7}$. Additionally, with an increase in the elderly population, dental and medical professions are required to pay more attention to the oral functions of the elderly, because maintaining and improving oral function leads to a long and healthy life ${ }^{25}$. Furthermore, dental professions are expected to play important roles in comprehensive community care, in collaboration with other medical professionals. Under these circumstances, Japanese dentists have realized that the active participation of dental hygienists is essential for addressing these various needs. Thus, dentists have educated dental hygienists in the knowledge and skills required at the above mentioned settings and have proposed to the national government to permit dental hygienists to be engaged in such services ${ }^{26,27}$.

In 2019, the aging rate in South Korea was $15.06 \%$, much lower than the $28.00 \%$ in $\operatorname{Japan}^{28)}$. However, the aging rate in Korea is predicted to exceed that of Japan around $2065^{29}$. Therefore, the knowledge and experience accumulated by Japan, a super-aged country, may be relevant and helpful to dental professionals in other developed countries, including Korea. These results may also contribute to the basic data for improving the quality of dental health care.

\section{Notes}

\section{Conflict of interest}

No potential conflict of interest relevant to this article was reported.

\section{Ethical approval}

This is a review-based study and does not require an IRB review.

\section{Author contributions}

Conceptualization: Sang-Hwan $\mathrm{Oh}$ and Masaru Sugiyama. Data acquisition: Rumi Nishimura and Masaru Sugiyama. Supervision: Masaru Sugiyama. Visualization: Myung-Jin Lee. Writing-original draft: Rumi Nishimura and Masaru Sugiyama. Writing-review \& editing: Sang-Hwan Oh.

\section{ORCID}

Masaru Sugiyama, https://orcid.org/0000-0001-6593-956X

Rumi Nishimura, https://orcid.org/0000-0003-3385-7329

Myung-Jin Lee, http://orcid.org/0000-0002-9267-4947

Sang-Hwan Oh, https://orcid.org/0000-0002-5944-0129

\section{References}

1. Miyatake K, Ishii T, Imanishi H; The Japan Association for Dental Hygienist Education: Dentist act. In: The Japan, ed. Health administration and social welfare. 2nd ed. Ishiyaku Publishers Inc., Tokyo, pp.31-35, 2007.

2. Miyatake K, Ishii T, Imanishi H; The Japan Association for Dental Hygienist Education: Dental hygienist act. In: The Japan, ed. Health administration and social welfare. 2nd ed. Ishiyaku Publishers Inc., Tokyo, pp.35-39, 2007.

3. Ministry of Health, Labor and Welfare: Working group on supply and demand issues for dentists. Retrieved February 15, 2021, from https://www.mhlw.go.jp/file/05-Shingikai10801000-Iseikyoku-Soumuka/0000087739.pdf(2015). 
4. Japanese Association for Dental Science: Deterioration of oral function. Retrieved February 15, 2021, from https://jads. jp/basic/pdf/document-180328-02_180816.pdf(2018).

5. Japanese Association for Dental Science: Developmental disorder of stomatognathic function. Retrieved February 15, 2021, from https://jads.jp/basic/pdf/document-200722-3.pdf(2020).

6. Ministry of Education, Culture, Sports, Science and Technology: List of university dental schools. Retrieved December 26, 2020, from https://www.mext.go.jp/a_menu/ koutou/iryou/1337432.htm(2020).

7. Japan Dental Association: The process of the dentist supply and demand problem and future opinion. Retrieved February 15, 2021, from https://www.mhlw.go.jp/file/05-Shingikai10801000-Iseikyoku-Soumuka/0000071236.pdf(2015).

8. Ministry of Health, Labor and Welfare: The standards to make questions for the National Examination for Dentists. Retrieved February 15, 2021, from https://www.mhlw.go. jp/file/05-Shingikai-10803000-Iseikyoku-Ijika/0000169910. $\operatorname{pdf}(2018)$.

9. Ministry of Education, Culture, Sports, Science and Technology: Model core curriculum for dental education. Retrieved February 15, 2021, from https://www.mext.go. jp/b_menu/shingi/chousa/koutou/035/gijiroku/__icsFiles/afie ldfile/2019/11/14/1422539_002.pdf(2017).

10. Common Achievement Tests Organization: Objective structured clinical examination. Retrieved February 15, 2021, from https://www.mhlw.go.jp/content/10804000/000560386.pdf(2 019).

11. Ministry of Education, Culture, Sports, Science and Technology: The outline of the model core curriculum for dental education. Retrieved December 26, 2020, from https://www.mext.go. jp/component/b_menu/shingi/toushin/__ icsFiles/afieldfile/2017/ 12/26/1383961_02_3.pdf(2017).

12. Ministry of Health, Labor and Welfare: Announcement of passing the 113th National Examination for Dentist. Retrieved February 15, 2021, from https://www.mhlw.go. jp/general/sikaku/successlist/2020/siken02/about.html(2020).

13. Ministry of Health, Labor and Welfare: The National Examination for Dentist. Retrieved February 15, 2021, from https://www.mhlw.go.jp/topics/2009/05/d1/tp0527-1h_0003. $\operatorname{pdf}(2010)$.

14. Ministry of Health, Labor and Welfare: Details of Japanese National Examination for Dentists (2014 revised version).
Retrieved February 15, 2021, from https://www.mhlw.go. jp/seisakunitsuite/bunya/kenkou_iryou/iryou/topics/dl/tp130 329-01_02.pdf(2014).

15. Ministry of Health, Labor and Welfare: Details of Japanese National Examination for Dentists (2018 revised version). Retrieved February 15, 2021, from https://www.mhlw.go. jp/file/05-Shingikai-10803000-Iseikyoku-Ijika/0000164152. $\operatorname{pdf}(2018)$.

16. Ministry of Health, Labor and Welfare: Study group on improving the quality of dentists. Retrieved February 15, 2021, from https://www.mhlw.go.jp/file/05-Shingikai-10801000Iseikyoku-Soumuka/0000099977.pdf(2015).

17. National Institute of Population and Social Security Research: Medical fee. Retrieved February 15, 2021, from http://www.ipss.go.jp/publication/j/shiryou/no.13/data/kaidai/ 04.html(2000).

18. PT-OT-ST.NET: Dysphagia rehabilitation. Retrieved February 15, 2021, from https://www.pt-ot-st.net/contents4/medicaltreatment- reiwa-2/1672(2020).

19. Saitama Dental Association: Support manual for dysphagia rehabilitation. Retrieved February 15, 2021, from https:// saitamada.or.jp/wp-content/themes/saitamada/pdf/go8020/a9. $\operatorname{pdf}(2014)$.

20. Kinki Regional Bureau of Health and Welfare: Outline of FY 2012 revision of medical fee. Retrieved February 15, 2021, from https://kouseikyoku.mhlw.go.jp/kinki/gyomu/gyomu/hoken_ kikan/documents/shika.pdf(2012).

21. Ministry of Health, Labor and Welfare: Cooperative guidance to in-home patients. Retrieved February 15, 2021, from https://www.mhlw.go.jp/stf/shingi/2r9852000001uo3f-att/2r 9852000001uo7c.pdf(2011).

22. Japan Dental Association: Involvement of dental care at home. Retrieved February 15, 2021, from https://www.med. or.jp/dl-med/jma/nichii/zaitaku/zleader01/zleader01_2-1.pdf (2017).

23. Ministry of Health, Labor and Welfare: Physician, dentist, and pharmacist statistics. Retrieved February 15, 2021, from https://www.mhlw.go.jp/toukei/saikin/hw/ishi/18/dl/kekka-2. $\operatorname{pdf}(2019)$.

24. The Japan Foundation for Aging and Health: Characteristics of Japan's super-aging society. Retrieved February 15, 2021, from https://www.tyojyu.or.jp/net/kenkou-tyoju/tyojyu-shakai/ nihon.html(2019). 
25. Watanabe $\mathrm{Y}$, Hirano $\mathrm{H}$, Arai $\mathrm{H}$, et al.: Relationship between frailty and oral function in community-dwelling elderly adults. J Am Geriatr Soc 65: 66-76, 2017. https://doi.org/10.1111/jgs.14355

26. Kikutani $\mathrm{T}$ : Manual for management of oral function. Soukousha Publishers, Inc., pp.1-51, 2010.

27. The Japan Association for Dental Hygienist Education: Request for revision of the standards for developing and selecting questions for the National Examination for Dental Hygienist. Retrieved March 3, 2021, from https://www. kokuhoken.or.jp/zen-eiky/publicity/file/test_revision.pdf(2015).

28. Global Note: World aging rate. Retrieved February 15, 2021, from https://www.globalnote.jp/post-3770.html(2020).

29. The Nikkei: Korea's aging population. Retrieved February 15, 2021, from https://www.nikkei.com/article/DGXMZO4 3047760Y9A320C1FF2000/(2019). 